\title{
Impacts of changes to trading hours of liquor licences on alcohol-related harm: a systematic review 2005-2015
}

\section{Claire Wilkinsona,b, Michael Livingstona and Robin Room ${ }^{a}$}

a Centre for Alcohol Policy Research, La Trobe University, Melbourne, Victoria, Australia

${ }^{b}$ Corresponding author: claire.wilkinson@latrobe.edu.au

\section{Article history}

Publication date: September 2016

Citation: Wilkinson C, Livingston M, Room R. Impacts of changes to trading hours of liquor licences on alcohol-related harm: a systematic review 2005-2015. Public Health Res Pract. 2016;26(4):e2641644. doi: http:// dx.doi.org/10.17061/phrp2641644

\section{Key points}

- Recent, robust studies demonstrate that reducing the hours during which onpremise alcohol outlets can sell alcohol late at night can substantially reduce rates of violence

- Increasing trading hours tends to result in higher rates of harm and restricting trading hours tends to reduce harm

- Findings are broadly consistent across an array of settings, with the exception of research studies on the relaxation of trading hours in England and Wales

- There is little research on the impact of restrictions of trading hours for packaged liquor (off-premise), although the limited research points towards effectiveness, particularly with respect to outcomes for teenagers and young adults

\section{Abstract}

Background: Legislative limits on trading hours for licensed premises have a long history in Australia as a key policy approach to managing alcohol-related problems. In recent years, following substantial extensions to permitted hours of sale, there has been renewed attention to policies aimed at reducing late-night trading hours. Restrictions on on-premise alcohol sales have been implemented in Australia after 3.30 am in Newcastle, and after 3 am in Kings Cross and the Sydney central business district in New South Wales. In July 2016, similar restrictions were introduced state-wide after 2 am, or 3 am in 'safe night precincts', in Queensland. Similar policy changes have occurred internationally (e.g. in the UK and the Nordic countries) and there is a growing body of research examining the impacts of trading hour policies on alcoholrelated harm. Although there has been a series of reviews of the research in this area, the most recent is now 5 years old and limited to studies published before March 2008

Objective and importance of study: To examine recent (2005-2015) research about the impact of changing the hours of sale of alcohol on alcoholrelated harms. The ongoing public discussion about trading hours policy in Australia can benefit from an up-to-date and comprehensive review of the research

Methods: Systematic review of the literature that considered the impact of policies that extended or restricted trading hours. MEDLINE, Core Collection, PsychINFO and EMBASE databases were searched from January 2005 to December 2015. Articles were summarised descriptively, focusing on studies conducted in Australia and published since the previous reviews.

Results: The search identified 21 studies, including seven from Australia. There were 14 studies published since previous reviews. A series of robust, well-designed Australian studies demonstrate that reducing the hours during which on-premise alcohol outlets can sell alcohol late at night can substantially reduce rates of violence. The Australian studies are supported by a growing body of international research.

Conclusion: The evidence of effectiveness is strong enough to consider restrictions on late trading hours for bars and hotels as a key approach to reducing late-night violence in Australia. 


\section{Introduction}

Alcohol consumption contributes to more than 200 different diseases, injuries or conditions. ${ }^{1}$ The overarching impact of alcohol consumption on health is large, with an estimated 5610 deaths attributed to alcohol in Australia in 2010 . $^{2}$ Researchers have identified an array of nonhealth problems (e.g. crime, family difficulties, absenteeism) that have strong associations with alcohol consumption.

Policies regulating alcohol availability are a key pillar of an evidence based approach to reducing the health and social burdens of alcohol consumption on the population. Major overviews of the field show that restrictions on physical availability, including trading hours, rank second only to pricing policy in effectiveness. ${ }^{3}$ In recent years, there has been a growing emphasis on the ways in which liquor licensing policy interacts with public health. One key area of concern is the availability of alcohol in a temporal sense, as measured by the allowable hours of trading for alcohol outlets (particularly late at night). This has been studied more closely for onpremise drinking outlets than for off-premise sales outlets. A major emphasis in studies of the effects of changes in hours of sale has been on assaults and violence in public places, and particularly late at night. Police, ambulance attendants, and emergency department doctors and nurses are keenly aware of the crescendo in cases of assault and injury on weekend nights, and of the strong association of intoxication with those cases. Increasingly, in Australia, as in other countries where there has been substantial extension of sales hours late at night, the question has arisen of whether reducing late-night sales hours would diminish rates of harm. The recent literature on the effects of changing the temporal availability of alcohol has increasingly focused on these effects late at night. ${ }^{4}$

A number of existing literature reviews examine the effects of changes in closing hours on rates of violence, including some that have also reviewed studies on density of outlets. ${ }^{3,5,6}$ A number of previous reviews also specifically examine the impact of trading hours on alcohol problems (particularly violence). ${ }^{7,8}$ Australian research was comprehensively reviewed in an earlier report by the National Drug Research Institute ${ }^{9}$, which summarised some particularly important interventions affecting Aboriginal and Torres Strait Islander communities in country towns and remote areas. These reviews only capture studies published until 2008, and there has been substantial subsequent research.

Previous reviews generally find that alcohol availability is a key driver of alcohol-related harm, with increased rates of alcohol-related harm in communities with higher densities of alcohol outlets (controlling for other relevant factors) and reductions in alcohol-related harm when late-night trading hours are reduced. But some recent reviews have raised concerns about the generalisability and policy relevance of this evidence. For example, Gmel et al. ${ }^{10}$ note that the specific relationships between particular outlet types and particular types of harm vary substantially between studies, meaning the implications of changes to alcohol availability may be highly context-specific.

In Australia and internationally, the trend for the past 40 years has been towards increasing the number of outlets, and minimising or abolishing limits on hours of the day and the week in which they are allowed to sell alcohol. This trend, motivated by various forces including policies encouraging market competition ${ }^{11}$, has generally continued until now, but during the past decade there has been some reversal in Australian public discourse about alcohol $^{12}$ and in public opinion about alcohol licensing controls. ${ }^{13}$ Despite the strong influence of alcohol industry interests, Australian governments have begun to respond to this shift in sentiment.

Following World War II, '6 o'clock closing' was repealed in all states where implemented. Later, in the 1970s and 1980s, standard trading hours for pubs were gradually extended. Most Australian studies of increase in general trading hours are from this earlier period. ${ }^{14,15}$ More recently, the idea of a new night-time economy took hold, focusing on late at night, after ordinary closing hours for on-premise alcohol sales (around 12 am in most Australian jurisdictions). ${ }^{4}$ As a British politician put it, "one of the few areas where we can develop jobs and where we can create wealth is in the alcohol industry and in the night-time economy". ${ }^{16}$

Recent increases in alcohol availability because of later closing hours have thus been because of extended closing permits, generally handled on a case-by-case basis. These extensions have often been liberally approved - for example, one-third of Victorian general (hotel) licences have a late-night trading licence. ${ }^{4}$ There have been two studies of such changes in the past 10 years from Western Australia. ${ }^{28,29}$ But the distinguishing mark of recent years, particularly in New South Wales (NSW), has been a trend back towards policy imposing earlier closing hours. Australian studies from the past 10 years that address restrictions on availability are thus primarily on restrictions imposing earlier closing hours. None of the studies reviewed previously have examined the impact of changes in late-night trading hours for off-premise outlets, an area that has been the subject of recent policy change in NSW.

With this in mind, this study summarises the recent evidence linking alcohol availability, in terms of trading hours and policies that restrict trading hours, with alcohol consumption and related harms, paying particular attention to studies relevant to the Australian policy context. Because of the recent focus on lockout policies (whereby no new patrons are allowed to enter a venue after a certain time but the venue can continue serving alcohol to people already inside) in Australia ${ }^{17}$, we also comment on studies that evaluate the effects of latenight lockouts. 


\section{Methods}

A systematic literature review was conducted in line with the Preferred Reporting Items for Systematic Reviews and Meta-Analyses (PRISMA) guidelines. ${ }^{18}$ The search was conducted in four electronic databases - MEDLINE, Core Collection, PsychINFO and EMBASE (Table 1).

The following search terms were used in each database: (alcohol OR liquor) AND (closing hour* OR opening hour* OR trading hour* OR operating hour* OR drinking hour* OR closing time* OR hours of alcohol sale* OR serving-hour $\left.{ }^{\star}\right)$. These searches were conducted using the 'title', 'abstract' and 'keywords' search fields, and limiting searches to records since 2005.

The process for identifying publications to be included in this review is presented in Figure 1. Returned results

Table 1. Electronic database search summary

\begin{tabular}{llc}
\hline $\begin{array}{l}\text { Database (citation } \\
\text { indexing service) }\end{array}$ & Discipline range & $\begin{array}{c}\text { Number } \\
\text { of records } \\
\text { returned }\end{array}$ \\
\hline $\begin{array}{l}\text { MEDLINE (Web of } \\
\text { Science) }\end{array}$ & $\begin{array}{l}\text { Medicine, biomedicine, life } \\
\text { sciences, public health, } \\
\text { clinical care and more }\end{array}$ & 41 \\
$\begin{array}{l}\text { Core Collection } \\
\text { (Web of Science) }\end{array}$ & $\begin{array}{l}\text { Multidisciplinary - a collection } \\
\text { of indexes including arts and } \\
\text { humanities, and social science }\end{array}$ & 65 \\
PsychINFO (OVID) & $\begin{array}{l}\text { Psychology and related } \\
\text { disciplines } \\
\text { Biomedical and }\end{array}$ & 60 \\
EMBASE (OVID) & $\begin{array}{l}\text { pharmaceutical } \\
\text { Total }\end{array}$ & $\mathbf{1 7 3}$ \\
\hline
\end{tabular}

were imported into EndNote and duplicates removed. From the 173 results, 49 duplicates were removed. The remaining 124 articles were screened for inclusion using article abstract only by the first two authors. Differences in exclusion/inclusion decisions were reconciled by the first author. Thirty-nine articles were retained for detailed reading (85 excluded). The main reason articles were excluded was because they did not study changes in alcohol outlet trading hours. Review articles were also excluded at this stage - rather, we used reviews to crosscheck our own search results.

We read the 39 articles to determine their relevance for inclusion. Of 39 studies, 23 were excluded and 5 were added (identified from researchers' own knowledge of the area and missing from the articles retrieved, and by cross-referencing our results with results from existing systematic reviews on trading hours for references since 2005 that were in scope). Exclusions at this stage were review articles, studies of association with no policy change (i.e. studies of association on trading hours and harms), commentary articles, studies about lockouts only and papers primarily concerned with methods. One study from Brazil was excluded because of the lack of a wellimplemented liquor-licensing system in that country. The included articles were summarised using Microsoft Excel.

\section{Results}

The 21 studies that examine the impact of changes in trading hours are summarised in Appendix 1 (available from: hdl.handle.net/1959.9/558712). The included studies were from Australia (7 studies), the UK (6), Canada (3), and one each from Germany, the Netherlands, Norway, Switzerland and the US. Most studies focused on urban areas, and 14 were

Figure 1. Process for identifying publications to be included in the review

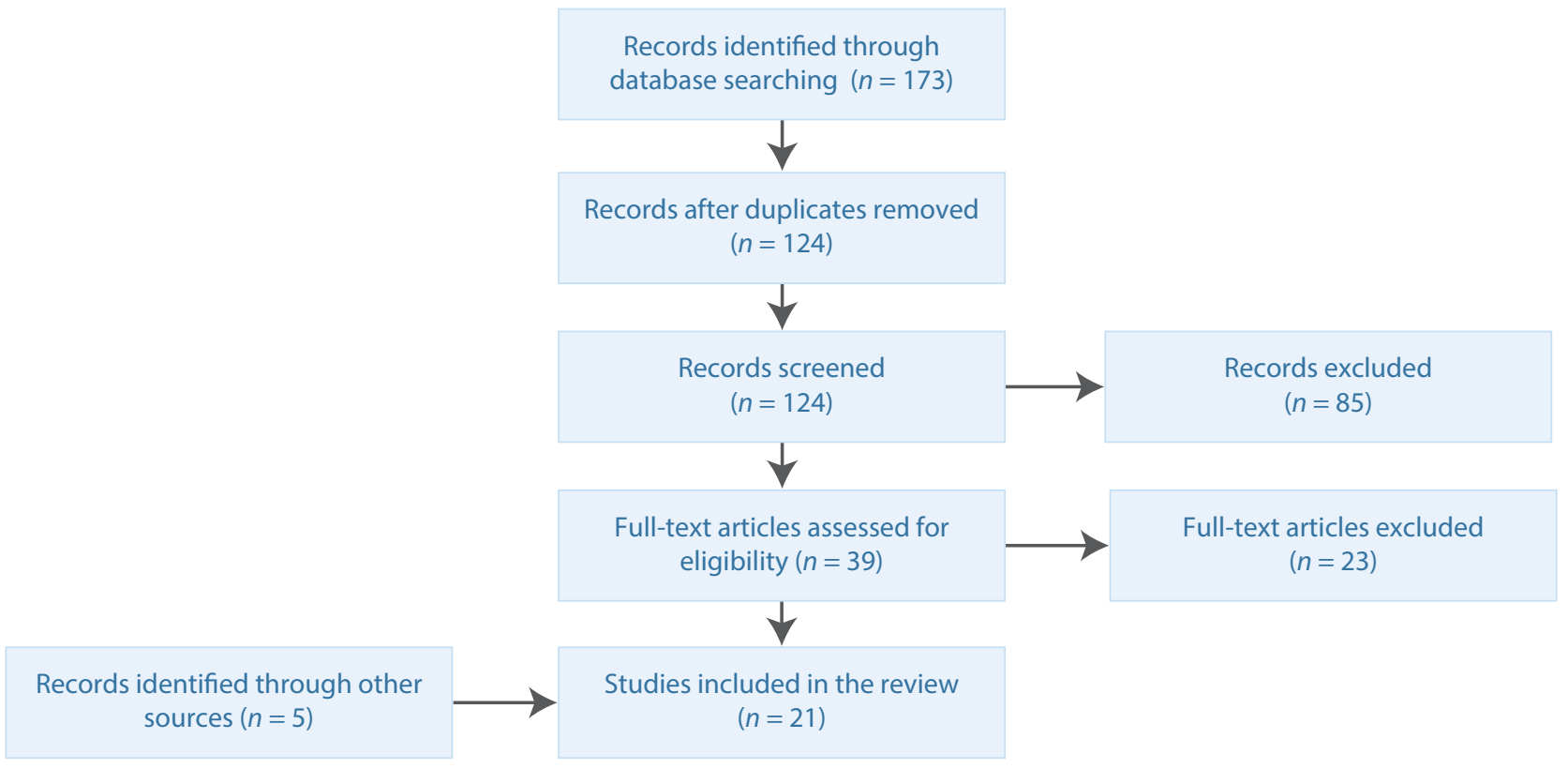


published since 2008, after the existing reviews of research in this area (e.g. Popova et al. ${ }^{6}$, Hahn et al. ${ }^{7}$ and Stockwell et al. $\left.{ }^{19}\right)$.

Most studies ( $n=14$ ) examined the impacts of increased trading hours; the remainder $(n=7)$ examined the impacts of restrictions on trading hours. Two examined the impacts of changing off-premise (packaged liquor) outlet trading hours, the remainder examined changes to on-premise outlets. Several of the Australian studies involved the combination of a change in closing hours with a lockout requirement earlier in the evening. We have included studies of the combined effects of lockouts and changes in closing hours, but not studies of the effect of a lockout alone. As noted below, the few studies in the latter category generally do not show any substantial effect.

The most compelling studies of effects of changes in closing hours come from recent restrictions introduced in different parts of NSW. In 2008, a range of restrictions were introduced on pubs' trading hours in the Newcastle central business district. This included restriction on the sale of shots after $10 \mathrm{pm}$, introduction of dedicated responsible service officers within venues and mandated closing at 3.30 am (initially $3 \mathrm{am}$ ), with a lockout from 1.30 am (initially $1 \mathrm{am}$ ). In a carefully designed study, Kypri et al. ${ }^{20}$ used the neighbouring area of Hamilton as a control to assess the impact of the Newcastle restrictions. Importantly, Hamilton implemented the same restrictions as Newcastle with the exception of the lockout and trading hour changes, meaning any differential effects could reasonably be attributed to these particular interventions. The study found a 37\% reduction in assaults in Newcastle between $10 \mathrm{pm}$ and 6 am. In a later follow-up, Kypri et al. ${ }^{21}$ showed that these reductions had been sustained during the 5 years following the intervention. The authors also showed that the majority of this reduction occurred after $3 \mathrm{am}$, with little impact evident between 1 am and 3 am, suggesting that the trading hour restrictions was the key policy, not the lockout. Studies that have specifically evaluated the effects of lockouts alone are rare and findings are mixed ${ }^{22,23}$, suggesting policies are better targeted at closing hours.

A similar set of interventions was subsequently implemented in the Sydney central business district and Kings Cross, a major Sydney entertainment district, in January 2014 (although there was no set closing time, alcohol could not be sold after 3 am, meaning venues effectively closed at the same time). In another well-designed study, Menendez et al. ${ }^{24}$ examined the impact of these restrictions on assault rates, with appropriate controls and tests for whether harms were simply displaced from the restricted areas to other parts of Sydney. They found strikingly similar results to the earlier Newcastle evaluation, with the number of assaults reduced by $26-32 \%$. There was little evidence of displacement to other areas (see also Donnelly et al. ${ }^{25}$ ). This is supported by a less robust study of presentations to an inner-Sydney emergency department that found reductions in alcohol-related presentations following the intervention, particularly late at night. ${ }^{26}$

Analyses from Miller et al. ${ }^{27}$ contrast Newcastle with Geelong and provide further evidence that trading hour restrictions are more effective than various policing and safety measures implemented in Geelong (e.g. safe taxi ranks, night-watch radio program, identification scanners, high-visibility policing). Another Australian study is based on granting extended trading permits to particular hotels in Perth, which showed some increases in traffic crashes $^{28}$, although the effects on the blood alcohol level of drivers who had been drinking at late-trading hotels were mixed. ${ }^{29}$

The most comprehensive study of late-night trading hour changes comes from Norway, where Rossow and Norström examined the impact of small changes $(<2$ hours) in allowable late-night trading for bars in 18 Norwegian cities. ${ }^{30}$ They found that each 1-hour change in trading hours was associated with a change of $16 \%$ in recorded assaults. This is the only study to include both extensions and restrictions on trading hours, and the findings were similar for changes in both directions, adding more evidence that effects were causally related to the policy changes.

An evaluation of extended trading hours in two entertainment precincts in Amsterdam, Netherlands, produced similar findings - a 34\% increase in alcoholrelated ambulance attendances in the intervention areas, occurring late at night and not matched in the control regions. ${ }^{31}$

There is some contrasting evidence from the removal of set licensing hours for pubs in England and Wales in 2005. Although an early study of one emergency department found some increases in harm following the relaxation of restrictions ${ }^{32}$, subsequent studies have not. Some of these studies did not take into account that there had already been substantial change in closing hours through specific public-entertainment licences and other extended-hours provisions for pubs. ${ }^{33}$ For example, Hadfield reports that the number of establishments in London's West End holding late-night opening permits more than tripled between 1992 and 2000, and their average capacity also grew. ${ }^{33}$ Four studies ${ }^{34-37}$ examined the impact of the changes to the law in 2005 on violence, but only one explicitly measured the degree to which extended hours were in operation before the law changes and the extent that venues actually took up the new extended hours on offer. ${ }^{36}$ None of the studies found any relationship between the removal of trading hour restrictions and violence rates; one study found that the extended trading hours reduced rates of traffic accidents. ${ }^{38}$ Similarly, analyses of a 1-hour extension of trading hours in two cities in Ontario, Canada, showed no impact on assault rates, although this study did not include appropriate control areas. ${ }^{39}$

The studies described here all focused on trading hours for on-premise alcohol outlets (bars, pubs and 
nightclubs). There is much less literature examining the impact of restrictions on packaged liquor trading. Two studies from Europe provide some evidence that reducing availability of packaged liquor late at night can reduce harm, particularly among young people. A Swiss study ${ }^{40}$ examined the impact of a combined reduction of outlet numbers (alcohol sales removed from video stores and gas stations) and hours (restrictions between $9 \mathrm{pm}$ and $7 \mathrm{am}$ ) and found a reduction of $25-40 \%$ in alcohol intoxication hospital admissions for teenagers and young adults. Similarly, a study of banning takeaway alcohol sales between 10 pm and 5 am in a German state found a significant reduction in hospitalisations among teenagers and young adults. ${ }^{41}$ It is worth noting that both studies come from settings where the baseline conditions involved a high degree of packaged alcohol availability late at night via convenience stores and similar establishments. There have been no studies of changes in packaged liquor trading hours in Australia.

\section{Discussion}

The literature examining the relationship between trading hours policy and related harms is relatively large and growing. The literature provides broadly consistent evidence that reducing the permissible trading hours of late-night venues is an effective way to reduce alcoholrelated harm (particularly violence). The Australian studies are well designed and consistent, and are supported by numerous studies internationally. The studies in England and Wales of what happened in 2005 when legislation raised the possibility of 24-hour trading did not show consistent effects.

The impact of restrictions on trading hours for packaged liquor is not as comprehensively studied as restrictions for on-premise consumption, although studies from outside Australia point strongly towards effectiveness, particularly with respect to outcomes for teenagers and young adults. ${ }^{40}$

The question also remains, particularly for the NSW studies, about the extent to which the lockout policy initiated along with the change in closing hours affected the results. Studies from Newcastle, where both a lockout and a mandated closing time were introduced, found that the reduction in violence occurred later in the night, pointing towards closing times as the key driver of effectiveness. ${ }^{20}$ At the time of the review, there were no studies of the Sydney restrictions that assess the times of night at which assaults have fallen.

\section{Limitations of the literature}

The research literature has several limitations. In several cases, studies that used a before and after design did not collect information on how widespread the actual implementation of permitted extensions in closing times was. There may have been little change in the availability and consumption of alcohol. Further, most of these studies did not include control sites or measures, meaning impacts could be related to factors other than the change in trading hours. Importantly though, differences in study results appeared to be more strongly related to the specific setting than the study quality. For example, even the best-quality studies of the UK policy changes ${ }^{36,38}$ showed no significant difference in harms following the extended trading hours, but the Australian studies with the strongest designs ${ }^{20,25}$ found significant effects of restricted trading hours. Finally, with respect to urban, regional and remote populations, most of the studies from the past 10 years have focused on urban areas. Evaluating the intervention in Queensland, where alcohol sales have been restricted after 2 am statewide since July 2016, could provide useful evidence on impacts on regional and remote areas.

\section{Conclusion}

A series of robust, well-designed studies from Australia demonstrate that reducing the hours during which onpremise alcohol outlets can sell alcohol late at night can substantially reduce rates of violence. Increasing trading hours tends to result in higher rates of harm, while restricting trading hours tends to reduce harm. The Australian studies are supported by research from Norway, Canada and the US, with the only exception being somewhat inconsistent findings from a relaxation of restrictions in England and Wales. ${ }^{36}$ The evidence of effectiveness is strong enough to consider restrictions on late-trading hours for bars and pubs as a key approach to reducing late-night violence in Australia.

\section{Acknowledgements}

This work is based on an Evidence Check review brokered by the Sax Institute for the NSW Ministry of Health. The Centre for Alcohol Policy Research is a joint undertaking of La Trobe University and the Foundation for Alcohol Research and Education. ML is supported by a National Health and Medical Research Council Early Career Fellowship (1053029).

\section{Competing interests}

$\mathrm{ML}$ is an unpaid board member of the Australian Rechabite Foundation, a charitable trust that supports research and community projects that aim to reduce alcohol-related harm.

\section{Author contributions}

CW led the writing of the article, conducted the searches and summarised half of the research articles. ML advised on the search strategy, summarised half of the research articles and contributed to writing the article. $R R$ contributed to writing the article. 


\section{References}

1. Rehm J, Mathers C, Popova S, Thavorncharoensap M, Teerawattananon Y, Patra J. Global burden of disease and injury and economic cost attributable to alcohol use and alcohol-use disorders. Lancet. 2009;373(9682):2223-33.

2. Ogeil RP, Gao CX, Rehm J, Gmel G, Lloyd B. Temporal changes in alcohol-related mortality and morbidity in Australia. Addiction. 2016;111(4):626-34.

3. Babor TF, Caetano R, Casswell S, Edwards G, Giesbrecht N, Graham K, et al. Alcohol: no ordinary commodity - research and public policy. Oxford: Oxford Medical Press; 2003

4. Manton E, Room R, Livingston M. Limits on trading hours, particularly late-night trading. In: Manton E, Room R, Giorgi C, Thorn M, editors. Stemming the tide of alcohol: liquor licensing and the public interest. Canberra: Foundation for Alcohol Research and Education, The University of Melbourne; 2014.

5. Holmes J, Guo Y, Maheswaran R, Nicholls J, Meier PS, Brennan A. The impact of spatial and temporal availability of alcohol on its consumption and related harms: a critical review in the context of UK licensing policies. Drug Alcohol Rev. 2014;33(5):515-25.

6. Popova S, Giesbrecht N, Bekmuradov D, Patra J. Hours and days of sale and density of alcohol outlets: impacts on alcohol consumption and damage: a systematic review. Alcohol Alcohol. 2009;44(5):500-16.

7. Hahn RA, Kuzara JL, Elder R, Brewer R, Chattopadhyay S, Fielding J, et al. Effectiveness of policies restricting hours of alcohol sales in preventing excessive alcohol consumption and related harms. Am J Prev Med. 2010;39(6):590-604.

8. Chikritzhs T, Stockwell T. The impact of later trading hours for Australian public houses (hotels) on levels of violence. J Stud Alcohol. 2002;63(5):591-9.

9. Chikritzhs T, Grey D, Lyons Z, Saggers S. Restrictions on the sale and supply of alcohol: evidence and outcomes. Perth: National Drug Research Institute, Curtin University of Technology; 2007

10. Gmel G, Holmes J, Studer J. Are alcohol outlet densities strongly associated with alcohol-related outcomes? A critical review of recent evidence. Drug Alcohol Rev. 2015; doi: 10.1111/dar.12304. [Epub ahead of print].

11. Room $\mathrm{R}$. The long reaction against the wowser: the prehistory of alcohol deregulation in Australia. Health Sociol Review. 2010;19(2):151-63.

12. Azar D, White V, Bland S, Livingston M, Room R, Chikritzhs T, et al. 'Something's brewing': the changing trends in alcohol coverage in Australian newspapers 2000-2011. Alcohol Alcohol. 2014;49(3):336-42.

13. Wilkinson C, Room R, Livingston M. Mapping Australian public opinion on alcohol policies in the new millennium. Drug Alcohol Rev. 2009;28(3):263-74.
14. Smith DI. Effect on traffic accidents of replacing 10 p.m. with 11 p.m. hotel closing in New South Wales, Australia. Perth: WA Alcohol and Drug Authority; 1987.

15. Smith DI. Effect on casualty traffic accidents of the introduction of 10 p.m. Monday to Saturday hotel closing in Victoria. Aust Drug Alcohol Rev. 1988;7(2):163-6.

16. Roberts M, Eldridge A. Planning the night-time city. London: Routledge; 2012.

17. McKenzie-Murray M. Inner-city lockout laws versus a 24-hour environment. The Saturday Paper. 2016 April 16; [cited 2016 Aug 18]; News [about 13 screens]. Available from: www.thesaturdaypaper.com.au/news/ politics/2016/04/16/inner-city-lockout-laws-versus-24hour-environment/14607288003130

18. Moher D, Liberati A, Tetzlaff J, Altman DG, PRISMA Group. Preferred reporting items for systematic reviews and meta-analyses: the PRISMA statement. Ann Inter Med 2009;151(4):264-9, W64.

19. Stockwell T, Chikritzhs T. Do relaxed trading hours for bars and clubs mean more relaxed drinking? A review of international research on the impacts of changes to permitted hours of drinking. Crime Prev Community Saf. 2009;11(3):153-70.

20. Kypri K, Jones C, McElduff P, Barker D. Effects of restricting pub closing times on night-time assaults in an Australian city. Addiction. 2011;106(2):303-10.

21. Kypri K, McElduff P, Miller P. Restrictions in pub closing times and lockouts in Newcastle, Australia five years on. Drug Alcohol Rev. 2014;33(3):323-6.

22. Mazerolle L, White G, Ransley J, Ferguson P. Violence in and around entertainment districts: a longitudinal analysis of the impact of late-night lockout legislation. Law \& Policy. 2012;34(1):55-79.

23. Miller P, Coomber K, Sønderlund A, McKenzie S. The long-term effect of lockouts on alcohol-related emergency department attendances within Ballarat, Australia. Drug Alcohol Rev. 2012;31(4):370-6.

24. Menéndez P, Weatherburn D, Kypri K, Fitzgerald J. Lockouts and last drinks: the impact of the January 2014 liquor licence reforms on assaults in NSW, Australia. Crime and Justice Bulletin, NSW Bureau of Crime Statistics and Research. 2015 Apr;183:1-12 [cited 2016 Aug 18]. Available from: www.bocsar.nsw.gov.au/ Documents/CJB/CJB183.pdf

25. Donnelly N, Weatherburn D, Routledge K, Ramsey S, Mahoney N. Did the 'lockout law' reforms increase assaults at The Star casino, Pyrmont? Sydney: NSW Bureau of Crime Statistics and Research, 2016 [cited 2016 Aug 18]. Available from: www.bocsar.nsw.gov. au/Documents/BB/Report-Did-the-lockout-law-reformsincrease-assaults-at-The-Star-casino-Pyrmont-bb114.pdf

26. Fulde GW, Smith M, Forster SL. Presentations with alcohol-related serious injury to a major Sydney trauma hospital after 2014 changes to liquor laws. Med J Aust. 2015;203(9):366. 
27. Miller P, Curtis A, Palmer D, Busija L, Tindall J, Droste N, et al. Changes in injury-related hospital emergency department presentations associated with the imposition of regulatory versus voluntary licensing conditions on licensed venues in two cities. Drug Alcohol Rev. 2014;33(3):314-22.

28. Chikritzhs T, Stockwell T. The impact of later trading hours for hotels on levels of impaired driver road crashes and driver breath alcohol levels. Addiction. 2006;101(9):1254-64.

29. Chikritzhs T, Stockwell T. The impact of later trading hours for hotels (public houses) on breath alcohol levels of apprehended impaired drivers. Addiction. 2007;102(10):1609-17.

30. Rossow I, Norstrom T. The impact of small changes in bar closing hours on violence. The Norwegian experience from 18 cities. Addiction. 2012;107(3):530-7.

31. de Goeij MCM, Veldhuizen EM, Buster MCA, Kunst AE. The impact of extended closing times of alcohol outlets on alcohol-related injuries in the nightlife areas of Amsterdam: a controlled before-and-after evaluation. Addiction. 2015;110(6):955-64.

32. Newton A, Sarker SJ, Pahal GS, van den Bergh E, Young C. Impact of the new UK licensing law on emergency hospital attendances: a cohort study. Emerg Med J. 2007;24(8):532-4.

33. Hadfield P. Bar wars: contesting the night in contemporary British cities. Oxford: Oxford University Press; 2006

34. Durnford AJ, Perkins TJ, Perry JM. An evaluation of alcohol attendances to an inner city emergency department before and after the introduction of the UK Licensing Act 2003. BMC Public Health. 2008;8:379.

35. Hough M, Hunter G. The 2003 Licensing Act's impact on crime and disorder: An evaluation. Criminology \& Criminal Justice. 2008;8(3):239-60.

36. Humphreys DK, Eisner MP. Do flexible alcohol trading hours reduce violence? A theory-based natural experiment in alcohol policy. Soc Sci Med. 2014;102:1-9.
37. Humphreys DK, Eisner MP, Wiebe DJ. Evaluating the impact of flexible alcohol trading hours on violence: an interrupted time series analysis. PloS One. 2013;8(2):e55581.

38. Green CP, Heywood JS, Navarro M. Did liberalising bar hours decrease traffic accidents? J Health Econ. 2014;35:189-98.

39. Vingilis E, McLeod Al, Mann RE, Seeley J. A tale of two cities: the effect of extended drinking hours in licensed establishments on impaired driving and assault charges. Traffic In Prev. 2008;9(6):527-33.

40. Wicki M, Gmel G. Hospital admission rates for alcoholic intoxication after policy changes in the canton of Geneva, Switzerland. Drug Alcohol Depend. 2011;118(2-3):20915.

41. Marcus J, Siedler T. Reducing binge drinking? The effect of a ban on late-night off-premise alcohol sales on alcohol-related hospital stays in Germany. J Public Econ. 2015;123:55-77.

42. Bouffard LA, Bergeron LE, Bouffard JA. Investigating the impact of extended bar closing times on police stops for DUI. J Crim Justice. 2007;35(5):537-45.

43. Vingilis E, McLeod Al, Seeley J, Mann RE, Beirness D, Compton CP. Road safety impact of extended drinking hours in Ontario. Accident Anal Prev. 2005;37(3):549-56.

44. Vingilis E, McLeod AI, Stoduto G, Seeley J, Mann RE. Impact of extended drinking hours in Ontario on motorvehicle collision and non-motor-vehicle collision injuries. J Stud Alcohol Drugs. 2007;68(6):905-11.

\section{Copyright: (c)}

(C) 2016 Wilkinson et al. This article is licensed under the Creative Commons Attribution-NonCommercial-ShareAlike 4.0 International Licence, which allows others to redistribute, adapt and share this work non-commercially provided they attribute the work and any adapted version of it is distributed under the same Creative Commons licence terms. See: www.creativecommons.org/licenses/by-nc-sa/4.0/ 